\title{
Knowledge, Barriers and Attitudes Towards Breast Cancer Mammography Screening in Jordan
}

\author{
Munir Ahmad Abu-Helalah ${ }^{1 *}$; Hussam Ahmad Alshraideh ${ }^{2}$,Ala-Aldeen Ahmad \\ Al-Serhan ${ }^{3}$, Mariana Kawaleet ${ }^{3}$, Adel Issa Nesheiwat ${ }^{3}$
}

\begin{abstract}
Background: Breast cancer is the most common type of cancer in Jordan. Current efforts are focused on annual campaigns aimed at increasing awareness about breast cancer and encouraging women to conduct mammogram screening. In the absence of regular systematic screening for breast cancer in Jordan, there is a need to evaluate current mammography screening uptake and its predictors, assess women's knowledge and attitudes towards breast cancer and screening mammograms and to identify barriers to this preventive service. Materials and Methods: This cross-sectional study was conducted in six governorates in Jordan through faceto-face interviews on a random sample of women aged 40 to 69 years. Results: A total of 507 participants with mean age of 46.8 \pm 7.8 years were interviewed. There was low participation rate in early detection of breast cancer practices. Breast self-examination, doctor examination and periodic mammography screening were reported by $34.9 \%, 16.8 \%$ and $8.6 \%$ of study participants, respectively. Additionally $3.8 \%$ underwent breast cancer screening at least once but not periodically, while $87.6 \%$ had never undergone mammography screening. Reported reasons for conducting the screening were: perceived benefit $(50 \%)$; family history of breast cancer (23.1\%); perceived severity (21.2\%); and advice from friend or family member (5.8\%). City residents have shown higher probability of undergoing mammogram than those who live in towns or villages. Results revealed negative perceptions and limited knowledge of study participants on breast cancer and breast cancer screening. The most commonly reported barriers for women who never underwent screening were: fear of results $(63.8 \%)$; no support from surrounding environment (59.7); cost of the test (53.4\%); and religious belief, i.e. Qadaa Wa Qadar $(51.1 \%)$. Conclusions: In the absence of regular systematic screening for breast cancer in Jordan, the uptake of this preventive service is very low. It is essential for the country of Jordan to work on applying regular systematic mammography screening for breast cancer. Additionally, there is a need for improvement in the current health promotion programmes targeting breast cancer screening. Other areas that could be targeted in future initiatives in this field include access to screening in rural areas and removal of current barriers.
\end{abstract}

Keywords: Barriers - mammogram - screening - breast cancer - Jordan

Asian Pac J Cancer Prev, 16 (9), 3981-3990

\section{Introduction}

Breast cancer is the most common type of cancer in Jordan. In the year 2010, it accounted for 37.4\% (941 cases) of all newly diagnosed female cancers $(n=2516)$. (Tarawneh et al., 2013) The median age at diagnosis for female breast cancer patients in Jordan is 50 , while the median age for males was 65.5. (Tarawneh et al., 2013) Regarding stage of breast cancer cases diagnosed in 2010 , only $3 \%$ of them were in situ, while $34 \%$ were localized, $45 \%$ were regional stage and $9 \%$ were distant metastasis. The remaining 9\% were classified as 'unknown stage'. (Tarawneh et al., 2013)

Mammogram is an effective screening tool for breast cancer. Results from clinical trials and case control studies showed that mammographic screening significantly reduces mortality due to breast cancer for women aged 50 to 74 years after seven to nine years of follow-up, regardless of screening interval or number of mammographic views per screen. Unfortunately regular systematic mammography screening for breast cancer has not been implemented in Jordan and screening mammogram is not free of charge in most centers. Current efforts are focused on annual campaigns aiming to increase awareness about breast cancer and encouraging women to conduct breast self-examination, be examined by doctors and conduct mammogram screening. (Kerlikowske et al., 1995)

The educational approach to health promotion aims to provide knowledge, information and necessary skills 
so that people will have sufficient knowledge when they make their own decision about engagement in a particular behaviour. The Health Belief Model (HBM), that originated 50 years ago, focuses on the role of knowledge and consequences of engagement in a particular behaviour. The information collected affects different components of the model; e.g.considering susceptibility to illness, weighing costs versus benefits, and noting cues to action. (Ogden, 2000) HBM has been validated in Jordan and other countries for studying predictors of breast cancer screening activities and for investigating barriers to this activity among non-attendants. (Cancer Prevention Directorate, 2006; Soskolne et al., 2007)

A survey from Israel on a random sample of 510 Muslim Arab women aged 50 to 69 years showed that statistically significant predictors of mammography screening for breast cancer were receiving a recommendation from a health professional or from family/friends, perceiving themselves as vulnerable to getting breast cancer, belief in the efficacy of the test, perceiving it as not painful, and being younger and/or more educated. (Valdini and Cargill, 1997).

Results from Malaysia showed that in the absence of regular systematic screening, the uptake of screening is low. Although some two-thirds of the sample knew about mammography (68\%), 15\% had a mammogram at least once in their life and only $2 \%$ had regular mammogram screening every two or three years. Significant predictors of being screened were age, family history of cancer, family history of breast cancer, regular supplement intake, regular medical check-up and knowledge about mammograms. Barriers to mammography screening in this study were lack of time, lack of knowledge, not knowing where to go for the test and a fear of the test. (Al-Naggar and Bobryshev, 2012).

Results from the Arab region shows that there is low screening uptake and limited knowledge of mammography screening. A cross-sectional study from Qatar showed that $26.9 \%$ of women 40 years of age or older had a mammogram once every year or two years and only $26.4 \%$ knew that mammography was recommended by national screening guidelines. This study revealed that Arab women in Qatar had limited knowledge of breast cancer and breast cancer screening. (Donnelly et al., 2014) Results consistent with recent findings from Saudi Arabia. (Radi, 2013)

In 2001, predictors of past mammography practice were studied at a private screening centre in Jordan. Results of this study showed that predictors of past mammography practice were women's family or personal history of breast tumours and receiving information about breast tumours from the media, in addition to obtaining information about mammograms from family members. (Petroc-Nustas, 2001)

A national survey was conducted in Jordan in 2006 to examine level of knowledge of Jordanian women about breast cancer and to assess their awareness of the importance of personal and clinical examination of the breasts. (Cancer Prevention Directorate, 2006) A random sample of 4751 women aged 20 or above took part in this survey and were selected randomly from all counties in
Jordan. Results showed that $53 \%$ of study participants who were not practicing breast self-examination (BSE) cited that they do not have any problem with their breast as a reason for not practicing this examination. The same study showed that only $5.7 \%$ of women older than 20 have had mammographic screening for breast cancer. (Cancer Prevention Directorate, 2006) The main limitation to this study was its focus on knowledge and barriers related to BSE not on mammography. (Semiglazov et al., 1992) BSE, however, has limited benefits when compared to mammographic screening in decreasing mortality and morbidity from breast cancer. (Semiglazov et al., 1992) These results are consistent with results from the region in countries that have not adopted regular systematic screening for breast cancer. (Amin et al., 2009; Fouladi et al., 2013)

It is essential, therefore, to investigate barriers to attending mammography screening for breast cancer in Jordan and to assess women's awareness of the importance of this screening test particularly with the current capacity building initiatives for breast cancer prevention in Jordan.

\section{Materials and Methods}

This cross-sectional study was conducted in six governorates in Jordan: Irbid and Jerash governorates in the north of Jordan; Amman, Zarqa and Balqa governorates in the middle of the country; and Karak governorate in the south of Jordan. This survey was conducted as face-toface interviews on a random sample of women aged 40 to 69 years, who are eligible for mammography screening according to the guidelines of the Jordan Breast Cancer Screening Committee.

Multistage cluster sampling technique was used in this study. Eight cities, six towns and eight villages were randomly selected. The main city in each governorate was stratified by socioeconomic status into low, middle and high ranges. A random sample was selected from each area.

\section{Eligibility criteria}

Inclusion criteria: Women aged 40 to 69 years (age eligibility according to national guidelines), speaks Arabic fluently and permanently lives in Jordan. Exclusion criteria: outside the age range of 40 to 69years, does not speak Arabic fluently, not living permanently in Jordan,, has lived in Jordan for less than one year, ,patients with psychiatric conditions, and those having difficulty in communication or any other medical condition limiting their ability to complete the survey.

Study questionnaire: A structured questionnaire was designed to cover the study objectives using the HBM. This questionnaire was developed based on the literature review, meeting with focus groups and our team's experience. It was tested and piloted in the study areas. Thirty questionnaires which were distributed during the pilot phase were not used in the final analysis.

The questionnaire assessed women's participation in the three early detection methods: breast selfexamination (BSE), breast examination by a doctor (DE) and mammography screening. Women who attended 
mammography screening were further asked whether or not they undergo the screening periodically and what their reasons were for going for mammography screening.

We also assessed participants' knowledge of breast cancer and awareness of the importance of mammography screening. The questionnaire also included sections on participants' attitudes, beliefs concerning breast cancer screening and potential barriers to undergoing this test.

Religious belief (i.e.Qadaa Wa Qadar), that God determines what will happen to me and when I will die, was included as a barrier for mammography screening based on results of the pilot phase.

"Cues to action" is an important component of the HBM. It covers factors that could increase engagement in certain behaviours. We included items in this survey related to factors that could increase the uptake of mammography screening (e.g. physician advice, making the test free in Jordan, health insurance coverage, presence of female technician and availability of transportation).

Data from the Department of Statistics showed that $14.2 \%$ of Jordanians live below the poverty line. (Department of Statistics)Cost of the mammography screening was, therefore, included as a barrier for undergoing the service. Women's opinion on the impact of removing the cost barrier was also assessed.

Demographic and socioeconomic characteristics of participants (e.g. age, residence, marital status, education, job, medical insurance, occupation and average monthly household income) were also included.

Patient's knowledge of risk factors and symptoms of breast cancer, and methods for early detection of the disease were assessed by asking them an open-ended question such as, "Can you tell me what are the causes of breast cancer?" This method measures a patient's recall, while other methods like choosing the risk factors from a list of factors, tends to measure a patient's recognition. (Gariballa et al., 1996)

Ethical approval was obtained from the Central Ethics Committee at the Faculty of Medicine at Mutah University. Regarding confidentiality of the data collected, no personal data such as participants' name, address, and telephone number was reported.

The questionnaire was administered through faceto-face interviews with women meeting the inclusion criteria and agreement to participate in the study. This was conducted by female medical students from the fourth to the sixth year of their academic study at Mutah University. These research assistants received two lectures on the topic and four training sessions on completing the study questionnaire; all training was conducted by the principal investigator

Eligible participants were interviewed alone unless they preferred to be accompanied by a friend or family member. Participants were free to not answer any question or to withdraw from the interview without being questioned. The research assistants were instructed to thank them for their time and taking part in the survey. At the end of the interview, participants were given a leaflet covering general information on breast cancer, benefits of early detection and advice on control of its risk factors.

\section{Sample size calculations}

Recent studies by the Cancer Prevention Directorate at the Jordanian Ministry of Health have shown that $30 \%$ of women aged 20 years or more who have not had a mammogram would know that mammograms can detect breast cancer before it is apparent to the patient. (Cancer Prevention Directorate, 2006)

Based on recent statistics from the Jordanian Department of Statistics, it is estimated that there are 536,502women aged between 40 and 69 years and eligible for mammographic screening for breast cancer in Jordan. (Department of Statistics; U.S Census Bureau, 2008) Based on this estimate, a sample of size of 323 would be sufficient to detect the above percentage at $95 \%$ confidence level and a 5\% margin of error. (Bland, 2000)

The above study also showed that only $5.7 \%$ of women older than 20 years had had mammographic screening for breast cancer in 2006. (Cancer Prevention Directorate, 2006) If we expected that this percentage has improved since the development of the Jordan Breast Cancer Program (JBCP) to reach 10\% (7.5\%-12.5\%), a sample size of 139 would be sufficient to represent women who have not had a mammogram in Jordan. For the estimation of other percentages, a sample of size 384 is needed at the same significance level and error margin. For the purpose of this study, it was agreed by the authors to have a sample size of 500 participantsas a conservative estimate.

\section{Statistical analysis plan}

Summary statistics including frequencies and percentages will be calculated for the categorical responses in the questionnaire. The Chi-square test will be used to assess any significant association between categorical variables. Mean, median and standard deviation will be reported for questions with continuous responses. Multinomial logistic regression model will be used to predict the response of participants who have undergone mammogram either on a periodic or not on a periodic basis referenced to those who have not undergone mammogram. (Bland, 2000)

\section{Results}

A total of 507 participants with mean age of $46.8 \pm 7.8$ years were interviewed between July 2014 and December 2014. A total of $57.1 \%$ of the sample were residents in cities, while $27.6 \%$ were residents in towns and the remaining $15.3 \%$ were residents in villages. Majority of the sample were married (77.9\%). Only $8.7 \%$ of the participants and $6.1 \%$ of the participants' husbands were illiterate. Around half of the sample (46.6\%) received health insurance from the Ministry of Health.

\section{Breast cancer early detection practices}

There was low participation rate in early detection of breast cancer practices amongst study participants. Breast self-examination, doctor examination and periodic mammography screening were reported by $34.9 \%$, $16.8 \%$ and $8.6 \%$ of study participants, respectively. Additionally $3.8 \%$ underwent breast cancer screening at least once but not periodically, while $87.6 \%$ had never 
Munir Ahmad Abu-Helalah et al

undergone mammography screening. Reported reasons for conducting the screening were: perceived benefit (50\%);family history of breast cancer (23.1\%); perceived severity $(21.2 \%)$; and advice from friend or family member $(5.8 \%)$.
Table 1 shows socioeconomic variables by history of mammography screening. Master degree or bachelor degree holders attended mammography screening either periodically or at least once more than those with lower educational status $(P<0.001)$. The same trend was observed

Table 1. Baseline Characteristics by Reported History of Mammography Screening

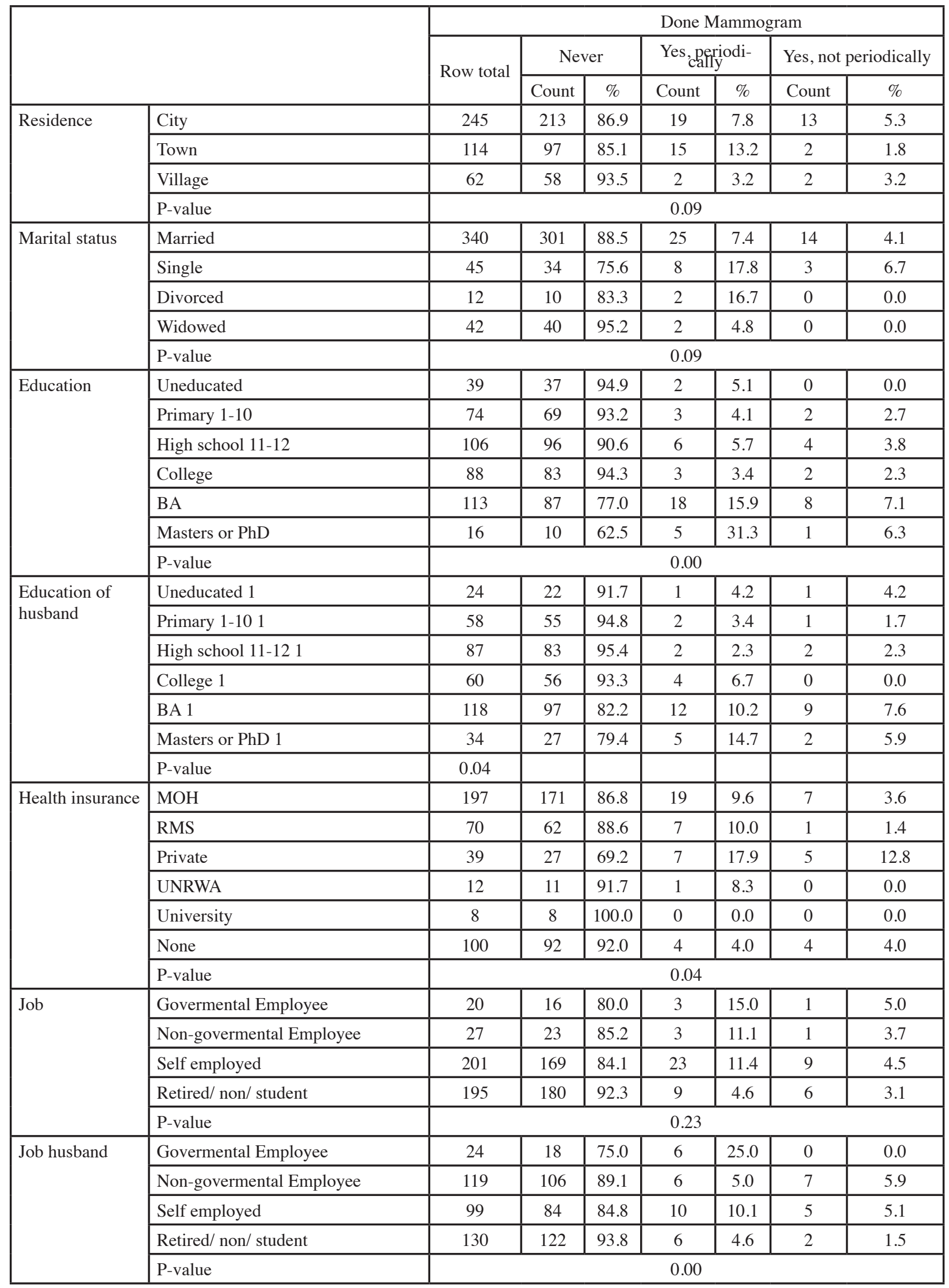




\begin{tabular}{|c|c|c|c|c|c|c|c|c|}
\hline \multirow[t]{6}{*}{ Family income } & $<500$ & 183 & 167 & 91.3 & 10 & 5.5 & 6 & 3.3 \\
\hline & $500-999$ & 119 & 106 & 89.1 & 9 & 7.6 & 4 & 3.4 \\
\hline & $1000-1499$ & 63 & 50 & 79.4 & 12 & 19.0 & 1 & 1.6 \\
\hline & 1500-1999 & 36 & 29 & 80.6 & 4 & 11.1 & 3 & 8.3 \\
\hline & $>2000$ & 26 & 20 & 76.9 & 3 & 11.5 & 3 & 11.5 \\
\hline & P-value & \multicolumn{7}{|c|}{0.02} \\
\hline \multirow{3}{*}{$\begin{array}{l}\text { Family history } \\
\text { of cancer }\end{array}$} & No & 275 & 246 & 89.5 & 20 & 7.3 & 9 & 3.3 \\
\hline & Yes & 144 & 120 & 83.3 & 16 & 11.1 & 8 & 5.6 \\
\hline & $\mathrm{P}$-value & 0.20 & & & & & & \\
\hline \multirow{3}{*}{$\begin{array}{l}\text { Family history } \\
\text { of breast cancer }\end{array}$} & No & 377 & 337 & 89.4 & 26 & 6.9 & 14 & 3.7 \\
\hline & Yes & 42 & 29 & 69.0 & 10 & 23.8 & 3 & 7.1 \\
\hline & P-value & \multicolumn{7}{|c|}{0.01} \\
\hline
\end{tabular}

for husband's education $(P=0.045)$. Women insured via the private sector were more likely to attend mammography screening than other participants $(P=0.043)$. High income was also associated with higher history of mammography screening, particularly for women with family monthly income of more than $2000 \mathrm{JD}(P=0.019)$.

Women with positive family history of breast cancer underwent mammography screening either periodically $(23.8 \%$ versus $6.9 \%)$ or not periodically $(7.1 \%$ versus $3.7 \%$ ) more often than women with no history of breast cancer $(P=0.006)$.

The above-mentioned variables were included into the multinomial logistic regression model as predictors for conducting mammogram. Model results based on the stepwise selection criteria have shown that only residence was a statistically significant predictor (model $P=0.062$ ). City residents have shown higher probability of undergoing mammogram at least once in their lifetime than those who live in towns or villages. The same pattern applied to undergoing mammogram periodically.

Knowledge of breast cancer and breast cancer screening

Most of the study participants reported that they heard of breast cancer $(96.8 \%)$ and $30.4 \%$ of them were aware that it is the second most frequent cause of death for women in Jordan. Regarding the methods of early breast cancer detection, $26.9 \%$ of the participants reported breast self-examination, $8.5 \%$ reported doctor examination, while $8.1 \%$ reported a combination of these two approaches. Screening mammography was reported by $7 \%$ of the participants. A little more than one-third of the participants $(36.2 \%)$ reported these three methods, while $13.2 \%$ of the participants reported that they did not know the answer. Around two-thirds of the sample (69.1\%) reported that they had heard of mammography screening.

Patients reported receiving information from physicians on breast cancer (43.9\%) and screening mammography $(39.2 \%)$. Moreover, $81.3 \%$ of the participants either agreed or strongly agreed that doctors' advice is necessary for them to undergo the mammography screening. A total of $76.1 \%$ of the participants reported 'Yes' to the statement "Mammography screening can detect breast cancer before its detection through doctor's examination".

When questioned about Jordanian guidelines for breast cancer screening, half of the participants provided the correct answer for the age criteria (49.7\%) and $60.4 \%$ of them agreed that age is a risk factor for breast cancer.

An interesting result was that $50.5 \%$ of the participants were aware about the difference between mammography screening, breast self-examination and doctor examination. Most of the participants either agreed (46.5\%) or strongly agreed with the statement (37.4\%) that breast cancer cure rates increase through early detection with mammography screening.

\section{Risk factors for breast cancer}

Only one participant reported five or more correct answers (out of 18 possible) to this open-ended question. Unexpectedly, $58.4 \%$ of the participants provided wrong answers to this question. Family history was the most commonly reported risk factor $(40.2 \%)$ followed by age $(10.5 \%)$, smoking (9.4\%), no breast-feeding (9.2\%) and personal history of breast cancer $(8.2 \%)$.

\section{Symptoms of breast cancer}

Similar to the findings about risk factors for breast cancer, study participants had also limited knowledge of breast cancer symptoms. Only $3 \%$ of the sample reported at least four of the eight common symptoms of breast cancer and $46.2 \%$ of the whole sample reported a wrong answer to this question. The most commonly reported symptoms were breast mass $(43.5 \%)$ followed by changes in breast shape or size $(16.5 \%)$ and unusual nipple secretions $(15.0 \%)$.

\section{Perceptions of breast cancer and breast cancer screening}

Participants' opinion on several statements related to breast cancer or breast cancer screening are summarized in Table 2. Participant's had differing opinions on the statement, "I think there is no cure for cancer."Nearly half $(45.8 \%)$ disagreed/strongly disagreed with this statement, while 35.8 of them agreed/strongly agreed with it.

The majority of participants $(55 \%)$ agreed/strongly agreed with the statement, "There is no change in my breast; that indicates I do not have cancer, and therefore there is no need for mammography screening." As expected, there was statistically significant differences between the groups in agreement with this statement 
Table 2. Perceptions of Breast Cancer and Breast Cancer Screening

\begin{tabular}{|c|c|c|c|c|c|c|c|c|c|}
\hline \multirow{3}{*}{ Question } & \multirow{3}{*}{ Category } & \multicolumn{2}{|c|}{ Summary } & \multicolumn{6}{|c|}{ Done Mammogram } \\
\hline & & \multirow{2}{*}{ Frequency } & \multirow{2}{*}{$\begin{array}{c}\text { Valid } \\
\text { Percentage }\end{array}$} & \multicolumn{2}{|c|}{ Never } & \multicolumn{2}{|c|}{ Yes, periodically } & \multicolumn{2}{|c|}{ Yes, not periodically } \\
\hline & & & & Count & $\%$ & Count & $\%$ & Count & $\%$ \\
\hline \multirow[t]{4}{*}{$\begin{array}{l}\text { I think there is no cure } \\
\text { from cancer }\end{array}$} & $\begin{array}{l}\text { Strongly } \\
\text { agree, agree }\end{array}$ & 162 & 35.8 & 132 & 35.9 & 14 & 41.2 & 4 & 25.0 \\
\hline & Neutral & 83 & 18.4 & 67 & 18.2 & 4 & 11.8 & 3 & 18.8 \\
\hline & $\begin{array}{l}\text { Strongly } \\
\text { disagree, } \\
\text { disagree }\end{array}$ & 207 & 45.8 & 169 & 45.9 & 16 & 47.1 & 9 & 56.3 \\
\hline & \multicolumn{3}{|c|}{ P-value } & \multicolumn{6}{|c|}{0.87} \\
\hline \multirow{4}{*}{$\begin{array}{l}\text { I do not have pain, this } \\
\text { indicates I have no breast } \\
\text { cancer, and therefore I } \\
\text { there is no need for me to } \\
\text { be screened }\end{array}$} & $\begin{array}{l}\text { Strongly } \\
\text { agree, agree }\end{array}$ & 195 & 41.8 & 173 & 45.4 & 5 & 13.5 & 5 & 31.3 \\
\hline & Neutral & 51 & 10.9 & 45 & 11.8 & 1 & 2.7 & 1 & 6.3 \\
\hline & $\begin{array}{l}\text { Strongly } \\
\text { disagree, } \\
\text { disagree }\end{array}$ & 220 & 47.2 & 163 & 42.8 & 31 & 83.8 & 10 & 62.5 \\
\hline & P-value & & & 0.00 & & & & & \\
\hline \multirow{4}{*}{$\begin{array}{l}\text { I have not noticed any } \\
\text { change in my breast, this } \\
\text { indicates I have no breast } \\
\text { cancer, and therefore there } \\
\text { is no need for screening }\end{array}$} & $\begin{array}{l}\text { Strongly } \\
\text { agree, agree }\end{array}$ & 129 & 55.0 & 225 & 59.2 & 6 & 16.2 & 9 & 52.9 \\
\hline & Neutral & 47 & 10.1 & 42 & 11.1 & 2 & 5.4 & 2 & 11.8 \\
\hline & $\begin{array}{l}\text { Strongly } \\
\text { disagree, } \\
\text { disagree }\end{array}$ & 163 & 34.9 & 113 & 29.7 & 29 & 78.4 & 6 & 35.3 \\
\hline & \multicolumn{3}{|c|}{ P-value } & \multicolumn{6}{|c|}{0.00} \\
\hline \multirow[t]{4}{*}{$\begin{array}{l}\text { I think mammogram causes } \\
\text { pain }\end{array}$} & $\begin{array}{l}\text { Strongly } \\
\text { agree, agree }\end{array}$ & 145 & 31.4 & 106 & 28.2 & 23 & 62.2 & 6 & 37.5 \\
\hline & Neutral & 160 & 34.6 & 141 & 37.5 & 3 & 8.1 & 2 & 12.5 \\
\hline & $\begin{array}{l}\text { Strongly } \\
\text { disagree, } \\
\text { disagree }\end{array}$ & 157 & 34.0 & 129 & 34.3 & 11 & 29.7 & 8 & 50.0 \\
\hline & P-value & & & 0.00 & & & & & \\
\hline \multirow[t]{4}{*}{$\begin{array}{l}\text { I think mammogram can } \\
\text { cause cancer }\end{array}$} & $\begin{array}{l}\text { Strongly } \\
\text { agree, agree }\end{array}$ & 110 & 23.9 & 92 & 24.4 & 10 & 27.0 & 1 & 5.9 \\
\hline & Neutral & 75 & 16.3 & 60 & 15.9 & 10 & 27.0 & 2 & 11.8 \\
\hline & $\begin{array}{l}\text { Strongly } \\
\text { disagree, } \\
\text { disagree }\end{array}$ & 276 & 59.9 & 225 & 59.7 & 17 & 45.9 & 14 & 82.4 \\
\hline & \multicolumn{3}{|c|}{$\mathrm{P}$-value } & \multicolumn{6}{|c|}{0.17} \\
\hline \multirow{4}{*}{$\begin{array}{l}\text { I think I have low risk of } \\
\text { cancer, therefore I do not } \\
\text { need to attend screening }\end{array}$} & $\begin{array}{l}\text { Strongly } \\
\text { agree, agree }\end{array}$ & 181 & 41.1 & 160 & 44.8 & 5 & 13.9 & 3 & 20.0 \\
\hline & Neutral & 77 & 17.5 & 66 & 18.5 & 2 & 5.6 & 4 & 26.7 \\
\hline & $\begin{array}{l}\text { Strongly } \\
\text { disagree, } \\
\text { disagree }\end{array}$ & 182 & 41.4 & 131 & 36.7 & 29 & 80.6 & 8 & 53.3 \\
\hline & P-value & & & 0.00 & & & & & \\
\hline \multirow{4}{*}{$\begin{array}{l}\text { I think I need to wait until } \\
\text { symptoms of breast can } \\
\text { appear before I go for } \\
\text { mammography screening }\end{array}$} & $\begin{array}{l}\text { Strongly } \\
\text { agree, agree }\end{array}$ & 212 & 45.4 & 188 & 49.3 & 4 & 10.8 & 7 & 41.2 \\
\hline & Neutral & 47 & 10.1 & 41 & \begin{tabular}{|l|}
10.8 \\
\end{tabular} & 2 & 5.4 & 1 & 5.9 \\
\hline & $\begin{array}{l}\text { Strongly } \\
\text { disagree, } \\
\text { disagree }\end{array}$ & 208 & 44.5 & 152 & 39.9 & 31 & 83.8 & 9 & 52.9 \\
\hline & \multicolumn{3}{|c|}{ P-value } & \multicolumn{6}{|c|}{0.00} \\
\hline
\end{tabular}


$(P<0.001)$.

Perceived risk was assessed through the statement, "I think I have low risk of breast cancer, and therefore, I do not need to undergo mammography screening." Some $44.8 \%$ of the participants agreed/strongly agreed and never underwentscreening; $20 \%$ of participants underwent screening but not periodically; and $13.9 \%$ of participants regularly underwent screening $(P<0.0001)$. Half of the participants who never underwent mammography screening (49.3\%) agreed/strongly agreed that they needed to wait until a mass or other symptoms appeared, compared with $10.8 \%$ of those regularly undergoing screening; and those undergoing non-periodic screening was $41.2 \%(P<0.0001)$. Interestingly, $23.9 \%$ of study participants agreed/strongly agreed with the statement, "I think that mammogram causes cancer."

Although the uptake of mammography screening was very low, $48.9 \%$ of the participants were aware of centres for mammography screening. Moreover, $14.9 \%$ of the participants reported knowing the national helpline for breast cancer programme and $40.8 \%$ were aware how to get the helpline number.

\section{Perceived barriers toward mammography screening}

Figure 1 shows selected barriers toward mammography screening grouped by screening status. The most commonly reported barriers for women who never underwent screening were: fear of results $(63.8 \%)$;no

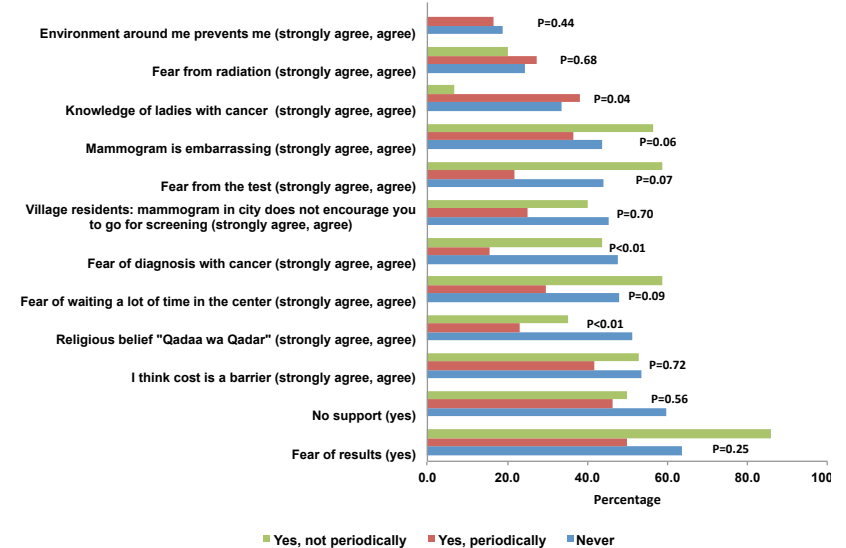

Figure 1. Perceived Barriers Toward Mammography Screening by Screening Status

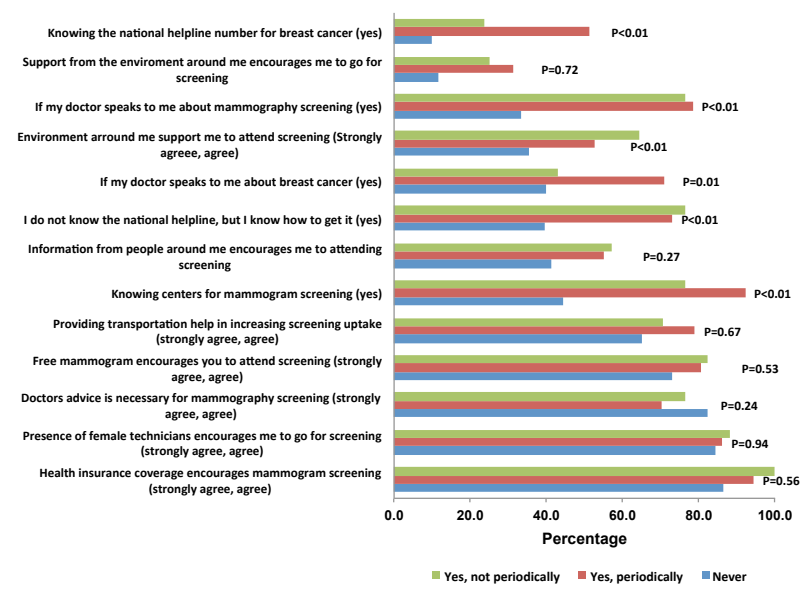

Figure 2. Cues for Action for Undergoing Mammography Screening support from surrounding environment (59.7); cost of the test (53.4\%); and religious belief i.e. Qadaa Wa Qadar, $(51.1 \%)$.

Cues for action for undergoingmammography screening

As seen in Figure 2, health insurance coverage or making mammography screening free are two of the most important factors reported by participants for increasing the uptake of screening. The former factor was reported by all patients who underwent mammography screening, but not those who underwent periodic screening, and by $86.3 \%$ of those who never underwent screening and $94.3 \%$ of those who regularly underwent screening. Presence of female technician(s) is another important factor that was reported by $88.2 \%, 86.1 \%$ and $84.3 \%$ of the previous three groups, respectively.

\section{Discussion}

This national survey assessed knowledge of breast cancer, mammography screening participation rate, barriers, attitudes and perceptions towards mammography screening among Jordanian women eligible for mammography screening.

This study showed that there is a low participation rate in early detection of breast cancer practices amongst study participants. In the absence of a nationwide regular screening programme for breast cancer, it was expected that a high rate of study participants would never have undergone a mammography screening; the rate was $87.6 \%$. Only $8.6 \%$ of study participants reported undergoing periodic screening, while $3.8 \%$ underwent breast cancer screening at least once but not periodically. Our results are consistent with those of other countries where no nationwide systematic screening programmes have been implemented. (Nur, 2010; Somanchi et al., 2010; Gang et al., 2013) . However, our results are lower than those from the neighbouring Arabic countries. (Radi, 2013; Donnelly et al., 2014) Results from Saudi Arabia revealed that $20.5 \%$ ever underwent mammography screening,(Radi, 2013) A recent study from Malaysia showed figures close to ours, where $74.5 \%$ of the participants had never undergone mammography screening and only about $8 \%$ reported having mammograms every one or two years. (Al-Naggar and Bobryshev, 2012)

Regarding regular screening uptake, our results are much lower than those from Israel for Muslim Arabic women as well as for those of Israel's total female population: regular mammography screening uptake rates are $20 \%$ and $60 \%$, respectively. (Soskolne et al., 2007), while $26.9 \%$ of Arab women in Qatar of 40 years of age or older had a mammogram once every year or two years. (Donnelly et al., 2014)

Regarding reasons for conducting mammography screening, the most commonly reported factors were: perceived benefit, family history of breast cancer, perceived severity and advice from friend or family member. These results are consistent with a previous small study from Jordan conducted in 2001 at a private screening centre. Predictors of past mammography practice were women's family or personal history of breast tumours 
and receiving information about breast tumours from the media, in addition to obtaining information about mammograms from family members. (Petroc-Nustas, 2001) Similar results were reported from a study on the general population of Malaysia. The most commonly reported reasons by Malaysian women were perceived benefit, doctor's advice and family history of cancer. (AlNaggar and Bobryshev, 2012)

The only statistically significant predictor for not undergoing mammography screening in our study was amongst participants living in villages. Two studies from Poland showed similar findings. (Spaczyński et al., 2009; PRAŻNOWSKA et al., 2010) A recent study on the practice of breast cancer prevention in four cities in China found that the uptake of mammography was higher in urban cities, such as Beijing, than rural regions. (Im Kim et al., 2011) Limited accessibility to health care facilities that offer this preventive service as well as individual perceptions in rural areas could justify these findings. (Im Kim et al., 2011) This means that future outreach programs in Jordan should target women in rural areas aiming to increase their mammography screening uptake.

Higher income and higher educational status are important socio-demographic characteristics of women undergoing regular screening. This is consistent with results of studies amongst Muslim Arab Israeli women, (Soskolne et al., 2007) Arab women in Qatar, (Donnelly et al., 2014) Ghana,(Opoku et al., 2012)married Chinese women in Yanbian. (Gang et al., 2013) Moreover, in our study, women who underwent screening had husbands with higher levels of education compared with those women who did not undergo screening. Low levels of education could negatively affect the screening practice. Possibly this is due to a lack of comprehension of health information and limited communication skills with doctors and other health care professionals. (DU et al., 2011; Jing, 2011)This indicates that more attention should be focused in future programmes on women with lower levels of education or lower socioeconomic class.

Knowledge of breast cancer and mammography screening have been identified as important predictors of screening uptake. (Schueler et al., 2008)There are high variations in this area of knowledge between countries and between different ethnic groups within the same country. Although most of our study participants reported that they had heard of breast cancer $(96.8 \%), 30.9 \%$ reported that they had never heard of mammography screening. These figures are close to those reported from Turkey where $32 \%$ of participants had no knowledge of mammography (Al-Naggar and Bobryshev, 2012). In a similar study conducted in Malaysia, $91.9 \%$ (n: 411) of women were aware about breast cancer. However, only half of them (n: 206; 50.1\%) were aware about mammography screening. (Yusof et al., 2014) In the study on Muslim Arab Israeli women, $25 \%$ of the women who had never undergone mammography screening reported that "never heard about it" was the main reason for not going for this screening test. (Valdini and Cargill, 1997)

Most of the participants (83.9\%) agreed that breast cancer cure rates increase through early detection with mammography screening. A similar finding was reported from Northwest Iran. (Fouladi et al., 2013)

Knowledge about risk factors was very limited with more than half of participants providing the wrong answer to this question. This is consistent with results from Saudi Arabia where the total knowledge score for the sample was low (with a median of 7.0 out of 14). (Amin et al., 2009) Family history was the most commonly reported risk factor (40.2\%) followed by age $(10.5 \%)$. This is consistent with a previous study from the United Kingdom (UK) where family history of breast cancer and a personal history of breast cancer were the most frequently cited risk factors. (Grunfeld et al., 2002)Unexpectedly, a small proportion of women in this study and in our study reported age as a risk factor. (Grunfeld et al., 2002)

Similar to the findings about risk factors for breast cancer, study participants also had limited knowledge of breast cancer symptoms. The most commonly reported symptom was breast mass followed by changes in breast shape or size. Our results are consistent with outcomes of recent study from Saudi Arabia, where breast lump and nipple discharge or bleeding were the most commonly reported symptoms. (Radi, 2013) It is important to increase women's awareness about symptoms other than a lump because misinterpretation of symptoms could lead to delay in diagnosis of breast cancer, as shown in previous studies. (Ramirez et al., 1999; Hamed and Fentiman, 2001)

Our results revealed that there is a high rate of negative perceptions about breast cancer and mammography screening. For example, one-third of participants agreed/ strongly agreed with the statement 'I think there is no cure for cancer'. Moreover, there was a low perceived risk of breast cancer amongst study participants and high rate of women who thought that they need to wait until symptoms of breast cancer appears before going for mammography screening. Results from two studies conducted in China showed that feeling that a mammogram was unnecessary (Gang et al., 2013) or absence of symptoms (Im Kim et al., 2011) were the main reasons of non-adherence to screening.

In our study women with family history of breast cancer attended mammography screening more than those with no such history $(P<0.005)$, however this factor was not a statistically significant predictor when it was entered in the logistic regression model. Several earlier studies found no association between a family history of breast cancer and an increased use of mammography. (Costanza et al., 1992)On the other hand, results from other studies showed that family history is an important and significant predictor of mammography use. (Murabito et al., 2001)

The most commonly reported barriers for women who never attended screening were fear of results $(63.8 \%)$, no support from surrounding environment $(59.65 \%)$, cost of the test $(53.4 \%)$ religious belief (i.e. Qadaa Wa Qadar $51.1 \%)$. Our results are consistent with previous studies. (Im Kim et al., 2011; Al-Dubai et al., 2012; Al-Naggar and Bobryshev, 2012; Gonzalez et al., 2012; Fouladi et al., 2013; Sarma, 2013; Cohen et al., 2015)Fear of the test results has been identified in several studies as one of the main barriers to mammography screening. (Azaiza and Cohen, 2006; Wu et al., 2006; Sadikoglu et al., 2010) Fear of a painful examination process is another important 
barrier reported in our study and several other studies. (Keshavarz et al., 2011; Fouladi et al., 2013)

Health education should include information to alleviate worries and fears related to the procedure (e.g. painful examination process). (Yucel et al., 2014) Information should also target some religious misconceptions such as the belief that they cannot do anything about their destiny (QadaaWa Qadar). Another area that needs to be covered is the very small radiation risk of developing breast cancer due to mammography, which was reported in our study and previous ones. (Lopez et al., 2009) Therefore, pre-mammography counselling is recommended to minimize fear and improve confidence in this preventive test. (Al-Naggar and Bobryshev, 2012)

We identified several factors that could increase screening uptake in our population such as receiving information from physicians on breast cancer and screening mammography. A meta-analysis on factors associated with mammography screening concluded that physician advice strongly influenced mammography utilization and tended to be even more important than socioeconomic factors. (Schueler et al., 2008). Recent study from Qatar reported that doctor advice and information from the Media were important predictors for awareness of breast self-examination or mammography screening. This is consistent with recent findings from Qatar. (Donnelly et al., 2014) This means that health care professionals in Jordan are very important stakeholders in breast cancer health promotion programmes.

Another issue in Jordan is that the poverty rate is high in comparison to the cost of the test. (Department of Statistics, 2013) Expectedly, health insurance coverage and making mammography screening free of charge were the main factors reported by participants for increasing the uptake of screening. Our results are consistent with previous studies that identified these two factors as important barriers to screening uptake. (Morales et al., 2004; Peek and Han, 2004; Chua et al., 2005)

A survey from the U.S. concluded that the relatively high cost of the procedure and the exclusion of mammography from medical insurance coverage were amongst the main barriers to mammography screening. The investigators predicted that if the cost factor was removed as one of the barriers, women's acceptance of mammography would subsequently improve (Valdini and Cargill, 1997).

In the absence of regular systematic screening for breast cancer in Jordan, the uptake of this preventive service is very low. However, there is also limited knowledge about breast cancer. We identified several barriers towards mammography screening. It is essential for the country of Jordan to work on applying regular systematic mammography screening for breast cancer.It's recommended to start with pilot projects in representative areas. Additionally, there is a need for improvement in the current health promotion programmes targeting breast cancer screening. Other areas that could be targeted in future initiatives in this field include access to screening in rural areas, and removal of current barriers (e.g. mainly categorized as the need for providing free mammography screening; knowledge and misconceptions related to breast cancer and/or mammography screening in Jordan).

\section{References}

Al-Dubai SAR, Ganasegeran K, Alabsi AM, et al (2012). Exploration of barriers to breast-self examination among urban women in Shah Alam, Malaysia: a cross sectional study. Asian Pac J Cancer Prev, 13, 1627-32.

Al-Naggar RA, Bobryshev YV (2012). Practice and barriers of mammography among Malaysian women in the general population. Asian Pac J Cancer Prev, 13, 3595-600.

Amin TT, Al Mulhim A, Al Meqihwi A (2009). Breast cancer knowledge, risk factors and screening among adult Saudi women in a primary health care setting. Asian Pac J Cancer Prev, 10, 133-8.

Azaiza F, Cohen M (2006). Health beliefs and rates of breast cancer screening among Arab women. $J$ Women's Health, 15, 520-30.

Bland M (2000). An Introduction to Medical Statistics, Oxford University Press.

Chua MST, Mok TS, Kwan WH, et al (2005). Knowledge, perceptions, and attitudes of Hong Kong Chinese women on screening mammography and early breast cancer management. Breast J, 11, 52-6.

Cohen EL, Wilson BR, Vanderpool RC, et al (2015). Identifying sociocultural barriers to mammography adherence among appalachian kentucky women. Health Commu, 10, 1-11.

Costanza ME, Stoddard AM, Gaw VP, et al (1992). The risk factors of age and family history and their relationship to screening mammography utilization. J Am Geriat Soc, 40, 774-8.

Department of Statistics J (2013). Poverty status in jordan.

Donnelly TT, Al Khater A-H, Al-Bader SB, et al (2014). Factors that influence awareness of breast cancer screening among arab women in qatar: results from a cross sectional survey. Asian Pac J Cancer Prev, 15, 10157.

DU J-1, ZHOU C-y, ZENG L-f (2011). Analysis on the General Survey Result of Gynecological Diseases in Tujia-Miao Autonomous Prefecture from 2006 to 2010 in Xiangxi. Chinese Primary Health Care, 9, 023.

Fouladi N, Pourfarzi F, Mazaheri E, et al (2013). Beliefs and behaviors of breast cancer screening in women referring to health care centers in northwest Iran according to the champion health belief model scale. Asian Pac J Cancer Prev, 14, 6857-62.

Gang M, Kim JI, Oh KO, et al (2013). Factors associated with mammography adherence among married Chinese women in Yanbian, China. Asian Pac J Cancer Prev, 14, 7207-13.

Gariballa S, Peet S, Fotherby M, et al (1996). The knowledge of hospital patients about vascular diseases and their risk factors. Postgrad Med J, 72, 605-8.

Gonzalez P, Castaneda SF, Mills PJ, et al (2012). Determinants of Breast, Cervical and Colorectal Cancer Screening Adherence in Mexican-American Women. J Commun Health, 37, 421-33.

Grunfeld E, Ramirez A, Hunter M, et al (2002). Women's knowledge and beliefs regarding breast cancer. British $J$ cancer, 86, 1373-8.

Hamed H, Fentiman I (2001). Benign breast disease. Int J Clin Practice, 55, 461-4.

Im Kim J, Oh KO, Li CY, et al (2011). Breast cancer screening practice and health-promoting behavior among Chinese women. Asian Nurs Res, 5, 157-63.

Jing L (2011). Survey of 1616 cases of gynecological diseases in different nationalities married women. Bull Dis Control Prev, 26, 67-8.

Kerlikowske K, Grady D, Rubin SM, et al (1995). Efficacy of screening mammography: a meta-analysis. Jama, 273, 149-54. 


\section{Munir Ahmad Abu-Helalah et al}

Keshavarz Z, Simbar M, Ramezankhani A (2011). Factors for performing breast and cervix cancer screening by Iranian female workers: a qualitative-model study. Asian Pac J Cancer Prev, 12, 1517-22.

Lopez ED, Khoury AJ, Dailey AB, et al (2009). Screening mammography: a cross-sectional study to compare characteristics of women aged 40 and older from the deep South who are current, overdue, and never screeners. Women's Health Issues, 19, 434-45.

Morales LS, Rogowski J, Freedman VA, et al (2004). Sociodemographic differences in use of preventive services by women enrolled in Medicare + Choice plans. Prev Med, 39, 738-45.

Murabito JM, Evans JC, Larson MG, et al (2001). Family breast cancer history and mammography: Framingham Offspring Study. Am J Epidemiol, 154, 916-23.

Nur N (2010). Breast cancer knowledge and screening behaviors of the female teachers. Women Health, 50, 37-52.

Ogden J 2000. Health psychology: a textbook, open university press. Buckingham.

Opoku SY, Benwell M, Yarney J (2012). Knowledge, attitudes, beliefs, behaviour and breast cancer screening practices in Ghana, West Africa. Pan African Medical Journal, 11.

Peek ME, Han JH (2004). Disparities in screening mammography. $J$ General Int Med, 19, 184-94.

Petroc-Nustas WI (2001). Factors associated with mammography utilization among Jordanian women. J Transcult Nurs, 12, 284-91.

Praznowska B, Puto G, Huras H (2010). Factors influencing the frequency of performing mammographic examinations - preliminary research. Med Ogolna, 16.

Program JBC. Jordan breast cancer program [Online]. Available: www.jbcp.jo.

Radi SM (2013). Breast cancer awareness among Saudi females in Jeddah. Asian Pac J Cancer Prev, 14, 4307-12.

Ramirez A, Westcombe A, Burgess C, et al (1999). Factors predicting delayed presentation of symptomatic breast cancer: a systematic review. Lancet, 353, 1127-31.

Sadikoglu G, Ozcakir A, Dogan F, et al (2010). Mammography utilization among Turkish women. Asian Pac J Cancer Prev, 11, 377-81.

Sarma EA (2013). Barriers to screening mammography. Health Psychol Rev, 1-21.

Schueler KM, Chu PW, Smith-Bindman R (2008). Factors associated with mammography utilization: a systematic quantitative review of the literature. J Women's Health, 17, 1477-98.

Semiglazov VF, Sagaidak VN, Moiseyenko VM, et al (1992). Study of the role of breast self-examination in the reduction of mortality from breast cancer. The Russian Federation/ World Health Organization Study. Eur J Cancer, 29, 203946.

Somanchi M, Juon HS, Rimal R (2010). Predictors of screening mammography among Asian Indian American women: a cross-sectional study in the Baltimore-Washington metropolitan area. J Women's Health, 19, 433-41.

Soskolne V, Marie S, Manor O (2007). Beliefs, recommendations and intentions are important explanatory factors of mammography screening behavior among Muslim Arab women in Israel. Health Educat Res, 22, 665-76.

Spaczynski M, Nowak-Markwitz E, Januszek-Michalecka L, et al (2009). Women's social conditions and their participation in Cervical Cancer Population Screening Program in Poland. Ginekol Pol, 80, 833-8 (in Polish).

Tarawneh M, Nimri O, Arkoob K, et al (2013). Cancer incidence in jordan 2010. non-communicable diseases directorate, jordan cancer registry. Minist Health.
Valdini A, Cargill LC (1997). Access and barriers to mammography in New England community health centers. $J$ Family Pract 45, 243-9.

Wu T-Y, West B, Chen Y-W, et al (2006). Health beliefs and practices related to breast cancer screening in Filipino, Chinese and Asian-Indian women. Cancer Detection Prev, 30, 58-66.

Yucel SC, Orgun F, Tokem Y, et al (2014). Determining the factors that affect breast cancer and self breast examination beliefs of Turkish nurses in academia. Asian Pac J Cancer Prev, 15, 1275.

Yusof A, Chia YC, Hasni YM (2014). Awareness and prevalence of mammography screening and its predictors - a cross sectional study in a primary care clinic in Malaysia. Asian Pac J Cancer Prev, 15, 8095-9. 